\title{
Investigation of fabric movement in a tumble dryer for the development of drying method for wool fabrics to save energy
}

\author{
Wei Bao ${ }^{1,2,3}$, Jinsong $\mathrm{Shen}^{4}$, Xiongying $\mathrm{Wu}^{5}$, Xuemei Ding ${ }^{2,3 *}$ \\ 1. College of Textile and clothing, Qingdao University, Qingdao 266071, China; \\ 2. College of Fashion and Design, Donghua University, Shanghai 200051, China; \\ 3. Key Laboratory of Clothing Design \& Technology (Donghua University), Ministry of Education, \\ Shanghai 200051, China; \\ 4. Textile Engineering and Materials (TEAM) Research Group, School of Fashion and Textiles, De \\ Montfort University, Leicester LE1 9BH, UK;
}

5. Shanghai Customs District 200135, China.

\begin{abstract}
Tumble dryers are widely used for drying garments, but felting shrinkage could be caused to wool garments during tumble drying process. In order to dry wool fabrics or garments in tumble dryers, flat dry function has been introduced in the dryers, however the energy efficiency is very low. The current study investigated the fabric movement at different rotation speeds in the tumble dryer and their resultant performances in terms of specific moisture extraction rate (SMER), evenness of drying, fabric shrinkage, and fabric smoothness. For shrink-resist treated wool fabrics, tumble drying at the rotation speed to keep fabric movement in projectile motion accompanied with tumbling occasionally could achieve better energy efficiency, drying uniformity and fabric smoothness. For untreated wool fabrics, introducing vertical movement to the flat dry in the tumble dryer can improve the heat exchange between the fabric and hot air, resulting in the increase of energy-efficiency by approximate $30 \%$ than flat drying motionlessly. Wool fabric shrinkage can be controlled to be less than $2 \%$ with the smooth appearance of fabric at grade 3.5 after drying under the recommended drying condition. This study could help tumble dryer manufacturers design optimal drying methods for wool fabrics with the potential for the reduction of energy consumption.
\end{abstract}

Key words: wool fabrics, tumble dryer, fabric movement, saving energy, shrinkage 


\section{Introduction}

Wool fiber is one of natural soft and comfortable materials used for garments. Wool based materials are highly popular with consumers, because wool fibers possess a combination of highly desired properties including outstanding thermal insulating power, excellent elasticity and biodegradability. ${ }^{1,2}$

In recent years, tumble dryers have been increasingly used for drying garments after washing. This may be because people need to dry clothes quickly in order to meet their busy working or social life. ${ }^{3,4}$ In America, $80.3 \%$ of households own one tumble dryer in $2015 .^{5}$ However, drying clothes in tumble dryer is an energy-intensive process. ${ }^{6}$ In general, US residential clothes dryers used approximately $60 \mathrm{TWh} /$ year, around $4 \%$ of the total US residential energy consumed in $2017 .{ }^{7}$ In UK, tumble dryers were amongst the top 16 energy consumed appliances used in the households. ${ }^{8,} 9$ For drying wool garments, tumble dryer is of limited use, because felting shrinkage of wool could be caused to damage the garment during tumble drying, which makes not only an economic loss but also a big waste of resources. On the domestic tumble dryer market, some tumble dryers have been modified to have the function for drying wool fabrics or garments by fitting a shelf in the tumble dryer to make wool materials laid flat and dried motionlessly. This method could solve the problem of wool felting shrinkage, but complement with more energy used due to the low drying efficiency.

Wool fibers have unique overlapping scales on the surface of the fibers. The configuration of surface structure of the fibers causes directional frictional effect (D.F.E.), which is responsible for the felting shrinkage occurring during laundering ${ }^{10,11}$ and tumble drying ${ }^{12}$. Therefore, wool garments are recommended to be washed gently by hand in order to avoid the unwanted shrinkage. When wool garment is washed in a washing machine, mechanical agitation plays an important role to influence the felting shrinkage of wool fabric during laundering. ${ }^{13}$ Currently on the market, the major types of washing machines used for garment washing are impeller and rotating drum washing machines. These washing machines are based on different mechanical action for the agitation of garment during washing. For impeller washing machine, the increase in the speed of the agitator could cause severer felting shrinkage of wool fabric, which was related to the number of flexes per unit time and the magnitude of the flexes at different speeds of the agitator. ${ }^{14}$ Currently the rotating drum machine is more popular in use. The previous research showed that felting severity of wool fabric during washing in the rotating-drum machine was lower than that in the impeller washing machine due to the different way and intensity of the mechanical action. ${ }^{15}$

During tumble drying, the mechanical action applied on fabrics under different 
rotation speeds of drum and the fabric movements plays an important role in the cause of felting shrinkage of wool. The impacting of wool fabric to the drum wall appears to have a smaller contribution to felting shrinkage than rubbing between fabrics in a tumble dryer. ${ }^{16}$ It was also found that at high speed of drum rotation fabric adhered to the wall of the drum and rotated with the drum in a tumble dryer, so that the shrinkage of wool fabric was the lowest due to the lowest level of mechanical action. ${ }^{16}$ However, the energy efficiency for drying wool fabrics in this way could be extremely low.

In order to improve the drying efficiency of garment and maintain their appearance in tumble dryers, fabric movement during tumble drying has been investigated by tracking the tracer fabric at varied rotation speeds of the drum. ${ }^{15,18}$ At the different rotation speeds of the drum from 35 to $60 \mathrm{rpm}$, fabric movement could be in the patterns of (a) sliding, (b) sliding and falling, (c) rotating and falling, (d) rotating in the previous study. ${ }^{15}$ It was found that fabric movement involving sliding, falling and rotating at the rotation speed of the drum between 45 and $50 \mathrm{rpm}$ could achieve drying at higher energy efficiency due to the increased contact area between fabric surface and hot air. ${ }^{15}$ Large contact area results in an increased transmission of heat from the drying air to the fabric surface, while more vapor of moisture from the textile surface to the drying air. ${ }^{17}$ In addition, evenness of drying was better at the medium-level rotation speed, which was attributable to less squeeze of fabrics and even contact between fabrics and drying air. ${ }^{18,}$ 19

Furthermore, fabric movement during tumble drying could influence the appearance of fabric in term of fabric smoothness. ${ }^{18}$ If the fabrics are folded and entangled or trapped for prolonged time, the smooth appearance will be poor ${ }^{18}$. Therefore, fabric movement could be an important factor for efficiency of drying as well as the performance of textile fabrics in the tumble dryers. However, previous researches on fabric motion and drying performances during tumble drying mainly focused on cotton fabrics rather than wool materials. ${ }^{17-19}$ The effect of fabric motion on drying performances of wool fabrics in a tumble dryer was rarely studied.

For wool fabric, felting shrinkage occurs progressively during tumble drying. In order to make wool fabric shrink resistance, various treatments have been developed. ${ }^{20-22}$ It is noted that the majority of wool labeled as machine-washable is treated by Chlorine-Hercosett process, which is a combination process of chlorination treatment and subsequent coating with polyamide-epichlorohydrin resin. ${ }^{22,23}$ Currently, both non machine-washable and machine-washable wool knitted garments are available on the market. A survey carried out by the research group at the beginning of 2019 showed that machine-washable wool knits accounted for around 18\% in the wool knits 
market in Shanghai China. The shrinkage behavior and shrinking mechanism of untreated and shrink-resist treated wool fabrics during the drying process are different ${ }^{12}$, so the drying program for wool fabrics or garments should be designed accordingly.

The current study was to investigate the fabric movement at different rotation speeds in the tumble dryer and their resultant performance in term of shrinkage, specific moisture extraction rate, evenness of drying and fabric smoothness for untreated and shrink-resist treated wool fabrics, on behalf of wool fabrics that are not machine-washable and machine-washable respectively. The fabric motions were identified corresponding to the rotation speed of drum during tumble drying. In order to prevent felting shrinkage of untreated wool fabric during tumble drying process and to improve the heat exchange between the fabric and hot air, the flat dry with vertical movement and projectile movement were explored and compared to the existing flat drying without motion used in the tumble dryer.

\section{Experiment details}

\subsection{Preparation of wool samples}

Untreated and Chlorine-Hercosett treated wool fabrics used, were made of merino wool with the mean fiber diameter of $19.5 \mu \mathrm{m}$ (Zhejiang XINAO Textile Inc., China). The scanning electron microscope (Hitachi, Flex SEM1000) images of untreated and treated wool fabrics are shown in Figure 1. Accelerating voltage of SEM was set to 5.00 $\mathrm{KV}$ and Working Distance was set to $8.5 \mathrm{~mm}$. The surface topography of untreated wool fibers shows clear cuticle scales, whereas Chlorine-Hercosett treated wool fibers show a smooth surface due to the partial degradation of cuticle scales by chlorination and polymer surface coating. ${ }^{12}$ Untreated wool was dyed with LANASET acid dye, whereas Chlorine-Hercosett treated wool was dyed with LANASOL reactive dye, which were common methods for wool dyeing. Both untreated and Chlorine-Hercosett treated wool samples were weft-knitted using 12 gauge flat knitting machine. The samples of wool fabrics were prepared by making into double layers with a size of $300 \mathrm{~mm} \times 400 \mathrm{~mm}$ and then sewing together around the three edges of the fabric samples. The marked size for measurement of fabric dimension was $220 \mathrm{~mm} \times 300 \mathrm{~mm}$. According to Test Method - TWC - TM309 Performance of Domestic Tumble Driers for "Hand Wash" Wool Products ${ }^{24}$, all fabric samples were relaxed by the relaxation procedure, i.e. being soaked in water once at $40^{\circ} \mathrm{C}$ for 30 minutes and then twice at $20^{\circ} \mathrm{C}$ for 2 minutes followed by flat drying. After flat drying, the fabric samples were conditioned at the standard atmosphere of $65( \pm 3) \% \mathrm{RH}$ and $20( \pm 2){ }^{\circ} \mathrm{C}$ for at least 24 hours. ${ }^{16}$ 


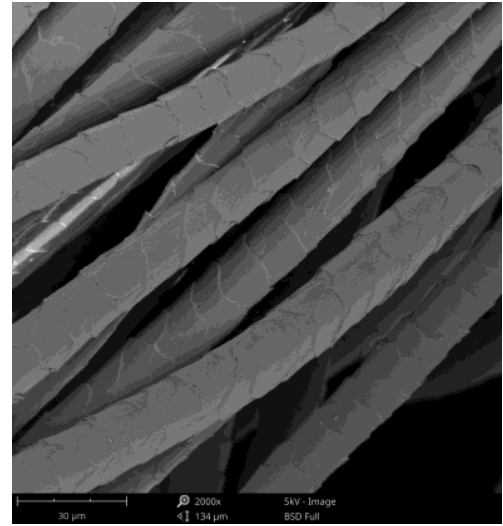

Untreated wool fabric $(\times 2000)$

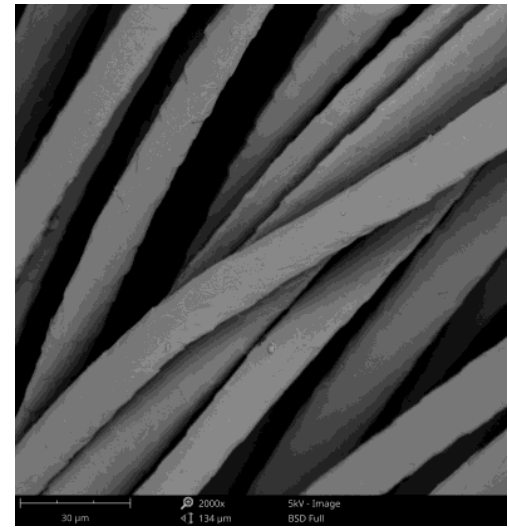

Chlorine-Hercosett treated wool fabric $(\times 2000)$

Figure 1 SEM images of untreated and shrink-resist treated wool fabrics

In order to control the initial moisture content on wool fabric samples prior to tumble drying, two untreated wool fabric samples and two Chlorine-Hercosett treated wool fabric samples along with wool fabric ballast making up to $2 \mathrm{~kg}$ totally, were soaked in water in the same way as the relaxation process. This simulated the hand-washing procedure. After soaking, the moisture content of all fabric loads was controlled to be $60 \%$ by spinning in a Haier top-load washer ${ }^{12}$ to be ready for drying process. The moisture content of fabric determined in the current study is the ratio of the mass of water to the mass of wool fabric that was conditioned at the standard atmosphere. $^{16}$

Alternatively, single piece of untreated wool fabric sample with the weight of approximately 65 grams was prepared to have the moisture content of $60 \%$ specifically for the comparison between projectile motion and motionless drying programs in the tumble dryer.

\subsection{Controlling parameters of drying programs in tumble dryer}

In order to explore drying methods for wool fabrics, the effect of fabric movements on the drying performances in the tumble dryer were investigated. The tumble dryer used in the study was a modified domestic thermoelectric air-vented dryer (GDZ10-977, Haier Co. Ltd, China) with adjustable parameters. ${ }^{25}$ The capacity of the tumble dryer is up to $10 \mathrm{~kg}$.

2.2.1 Tumble drying of wool fabrics with drying load of $2 \mathrm{~kg}$ in the tumble dryer

For the experiments with the normal fabric load of $2 \mathrm{~kg}$, different fabric movements 
were controlled by adjusting rotation speed of the drum according to the previous study. ${ }^{16}$ Rotation speed of the drum was set to $16 \mathrm{rpm}, 35 \mathrm{rpm}, 51 \mathrm{rpm}$ and $67 \mathrm{rpm}$ respectively to perform different fabric motions. Heater power $(3000 \mathrm{~W})$ and air flow velocity $(5.5 \mathrm{~m} / \mathrm{s})$ were the fixed parameters. The total drying time was set based on the preliminary experiment in which the drying time required was recorded when the moisture content of the whole load reached to $6 \%$ or less. However, the final moisture contents at the end of drying under different drying cycles at the same parameters or at different rotation speed of the drum could be various. Table 1 summarized the drying parameters used and the final moisture contents of the whole load at different rotation speeds of the drum which were in the range from $0.8 \%$ to $4.0 \%$. It was noted that the total drying time at $67 \mathrm{rpm}$ rotation speed of the drum was much longer than others, which was explained in Section 3.1.1.

Table 1 Parameters of drying programs and moisture content of fabrics under tumble drying at heater power of $3 \mathrm{~kW}$ and air flow velocity of $5.5 \mathrm{~m} / \mathrm{s}$

\begin{tabular}{|c|c|c|c|c|c|c|}
\hline $\begin{array}{c}\text { Amount } \\
\text { of load } \\
(\mathrm{kg})\end{array}$ & $\begin{array}{c}\text { Drying } \\
\text { testing } \\
\text { No. }\end{array}$ & $\begin{array}{c}\text { Rotation } \\
\text { speed of the } \\
\text { drum (rpm) }\end{array}$ & $\begin{array}{c}\text { Fabric movement } \\
\text { during tumble drying }\end{array}$ & $\begin{array}{c}\text { Initial } \\
\text { moisture } \\
\text { content }(\%)\end{array}$ & $\begin{array}{l}\text { Total drying } \\
\text { time }(\min )\end{array}$ & $\begin{array}{l}\text { Final moisture } \\
\text { content of the } \\
\text { whole load } \\
(\%)\end{array}$ \\
\hline \multirow{4}{*}{2} & 1 & 16 & $\begin{array}{c}\text { Tumbling in a small } \\
\text { area }\end{array}$ & & 44.0 & 3.6 \\
\hline & 2 & 35 & $\begin{array}{l}\text { Projectile motion } \\
\text { accompanied by } \\
\text { tumbling occasionally }\end{array}$ & 60 & 33.5 & 2.7 \\
\hline & 3 & 51 & $\begin{array}{c}\text { Projectile and } \\
\text { rotating* motion }\end{array}$ & & 38.5 & 0.8 \\
\hline & 4 & 67 & Rotating* & & 360.5 & 4.0 \\
\hline
\end{tabular}

Rotating* refers to the fabric sample adhered to the drum wall and rotated with the drum in the tumble dryer.

The effect of the rotation speed of the drum on the fabric movement has been discussed in the previous study. ${ }^{16}$ Figure 2 shows fabric movements at different rotation speeds of the drum during tumble drying process. At a low drum rotation speed (16 rpm), fabrics were repeatedly lifted by lifters and fell down, i.e. tumbled in a small area of the drum during tumble drying (Fig. 2a), in which the main mechanical action applied on 
fabrics is the rubbing between fabric samples. With increasing the rotation speed of the drum, the track area of fabric movement became bigger. At $35 \mathrm{rpm}$ of rotation speed, projectile motion of fabrics was apparent, and accompanied occasionally with tumbling motion (Fig. 2b). At this fabric motion, both rubbing and impact forces apparently acted on fabrics. When the rotation speed of drum reached $51 \mathrm{rpm}$, fabrics nearly rotated with the drum to the higher position, and then they were thrown into air and fell down freely (Fig. 2c). Therefore, the main movement is the rotating and projectile motion in which way the main mechanical action on fabrics is impact force. When the drum rotation speed increased further to $67 \mathrm{rpm}$, the fabric sample adhered to the drum wall and rotated with the drum (Fig. $2 \mathrm{~d}$ ), therefore little rubbing or impacting force occurred. ${ }^{16}$

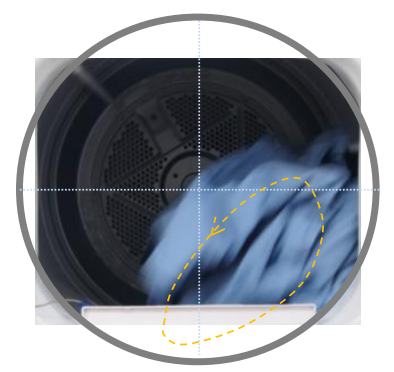

(a) $16 \mathrm{rpm}$

Tumbling in a small area

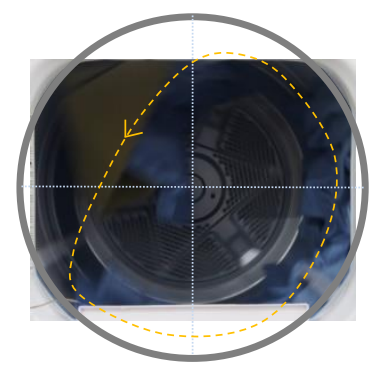

(c) $51 \mathrm{rpm}$

Projectile and partial rotating motion

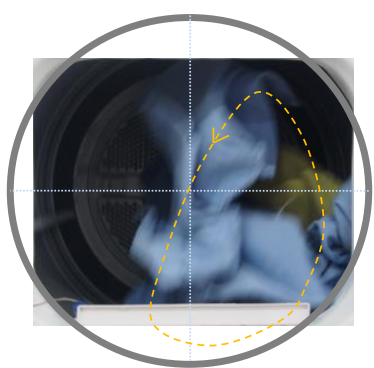

(b) $35 \mathrm{rpm}$

Projectile motion with tumbling occasionally

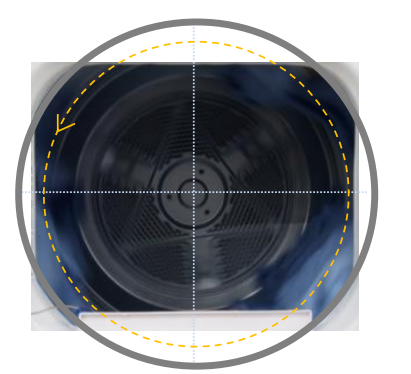

(d) $67 \mathrm{rpm}$

Fully rotating motion

Figure 2 Photographs and schematic diagrams of main fabric motion trajectory at different rotation speeds of the drum: (a) $16 \mathrm{rpm}$, (b) $35 \mathrm{rpm}$, (c) $51 \mathrm{rpm}$ and (d) $67 \mathrm{rpm}$.

\subsubsection{Tumble drying of single piece of wool fabric in tumble dryer}

Flat dry without fabric motion was investigated using single piece of wool fabric in tumble dryer. The rotation speed of the drum was set to 0 , and a perforated shelf was fit in the drum to hold the single piece of fabric sample (around $0.065 \mathrm{~kg}$ ) laid flat to dry 
motionlessly (Figure 3a). Alternatively, a fabric sample was laid flat on the perforated shelf but moved up and down manually at around 45 cycles per minute using the control handle through the hole of the door of the tumble dryer (Figure $3 b$ ). The vertical moving distance is around $20 \mathrm{~cm}$.

For comparison, projectile drying of single wool fabric was carried out as shown in Figure $3 \mathrm{c}$, the rotation speed of the drum was set at $31 \mathrm{rpm}$ to achieve projectile motion, in which the fabric sample was lifted by the lifter, projected into air, impact on the drum wall, slid backward against the rotation direction of the drum, and then repeat the whole motion. Therefore, both projectile motion and sliding motion of fabric were involved. It was noted that after the fabric was projected into the air, the impact position of the fabric onto the drum wall was close to the lifter, and then the fabric was lifted almost immediately to progress the next cycle of projectile motion, therefore, sliding between the fabric and drum wall is minimum. It can be assumed that fabric mainly experienced projectile motion at the drum rotation speed of $31 \mathrm{rpm}$.

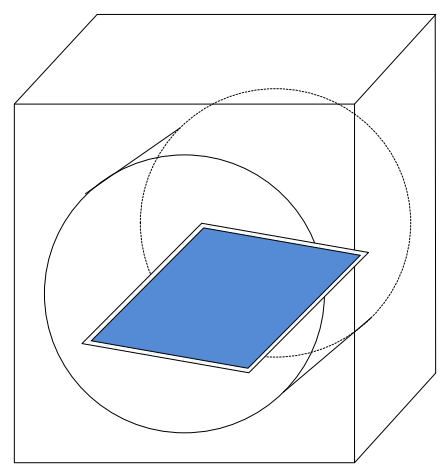

(a) Flat (motionless)

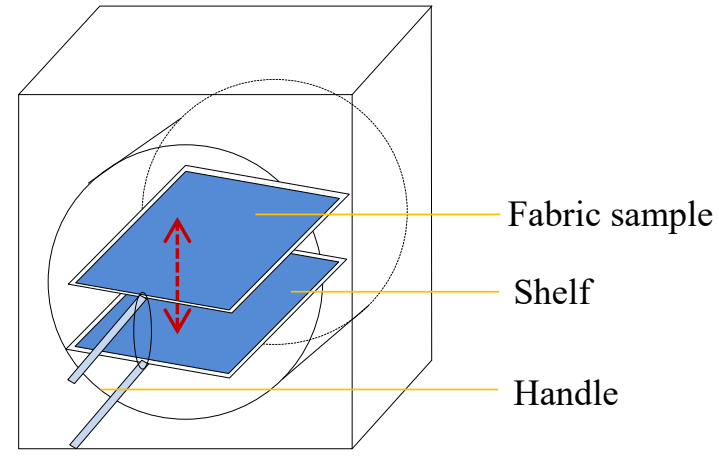

(b) Flat moving up and down (vertical reciprocating movement)

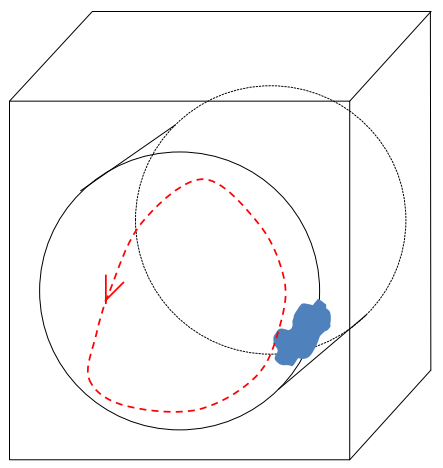

(c) Projectile motion

Figure 3 Schematic diagrams of fabric in projectile motion or fabric held on shelf in the tumble dryer 
Apart from the fabric motion, other drying parameters for heater power and air flow velocity were kept same as that in experiments with the load of $2 \mathrm{~kg}$. The parameters are summarized in Table 2. The drying process was stopped when the moisture content of the whole load was lower than $6 \%$.

Table 2 Parameters of drying programs and moisture content of fabrics during tumble drying of single piece of wool fabric sample at heater power of $3 \mathrm{~kW}$ and air flow velocity of $5.5 \mathrm{~m} / \mathrm{s}$

\begin{tabular}{ccccccc}
\hline $\begin{array}{c}\text { Amount } \\
\text { of load } \\
(\mathrm{kg})\end{array}$ & $\begin{array}{c}\text { Drying } \\
\text { testing } \\
\text { No. }\end{array}$ & $\begin{array}{c}\text { Rotation } \\
\text { speed of } \\
\text { the drum } \\
(\mathrm{rpm})\end{array}$ & $\begin{array}{c}\text { Fabric movement during } \\
\text { tumble drying }\end{array}$ & $\begin{array}{r}\text { Initial } \\
\text { moisture } \\
\text { content } \\
(\%)\end{array}$ & $\begin{array}{c}\text { Total } \\
\text { drying } \\
\text { time } \\
(\mathrm{min})\end{array}$ & $\begin{array}{c}\text { Final } \\
\text { moisture } \\
\text { content of the } \\
\text { whole load } \\
(\%)\end{array}$ \\
\hline $\begin{array}{c}\text { (single } \\
\text { piece of } \\
\text { fabric })\end{array}$ & 1 & 0 & Flat dry (Motionless) & & 21.7 & 4.7 \\
\hline
\end{tabular}

\subsection{Assessment of drying performance}

\subsubsection{Specific moisture extraction rate (SMER)}

SMER $(\mathrm{kg} / \mathrm{kWh})$ is the ratio between the amount of evaporated water and the total energy supply, which could be determined by Equation (1). A high SMER would indicate an efficient drying process with low energy consumed. ${ }^{26}$

$$
\mathrm{SMER}=\frac{W_{b}-W_{a}}{Q}
$$

Where SMER is specific moisture extraction rate of a drying process, $W_{b}$ is the weight of whole fabric load before drying, $W_{a}$ is the weight of whole fabric load after drying, $Q$ is the electricity used for heating by the heater during drying process. Electricity used by the fan and the motor was much less than the heater. Hence, electricity consumption of the fan and the motor was not included when calculated.

\subsubsection{Evenness of drying}

Evenness of drying is an important testing criterion to assess performance of fabric drying. According to GB/T 20292-2006 Tumble dryers for household use-Methods for measuring the performance ${ }^{27}$, evenness of drying is the standard deviation of the final 
moisture contents of each wool fabric samples. It could be determined by Equation (2). The lower is the evenness of drying, the better is the drying uniformity.

$$
\mathrm{S}=\sqrt{\frac{1}{k} \sum_{j=1}^{k}\left(\mu_{j}-\bar{\mu}\right)^{2}}
$$

In which, $S$ is evenness of drying, $k$ is the number of fabric samples, $j$ is the fabric sample number, $\mu_{j}$ is the final moisture content of fabric sample number $j, \bar{\mu}$ is the average of final moisture content of the samples.

\subsubsection{Fabric smoothness grade}

Fabric smoothness grade is used to evaluate the smoothness appearance of fabric specimens. With reference to AATCC Test Method 124-2014 Smooth appearance of fabrics after repeated home laundering ${ }^{28}$, two trained observers rated each test specimen independently according to Smoothness Appearance replicas (grade 1 to 5, "grade 1" means severely wrinkled appearance, "grade 5" means very smooth appearance). Fabric smoothness grade of each test specimen was the average of the results rated by two train observers.

\subsubsection{Dimensional change of wool fabrics}

The change in length of wool fabric samples in warp direction, called as "length change", was used to characterize dimensional change of wool fabric. It was calculated using Equation (3) based on AATCC Test Method 135-2014 Dimensional Changes in Automatic Home Laundering of Woven or Knitted Fabrics ${ }^{29}$.

$$
L C=\frac{B-A}{A} \times 100 \%
$$

Where $L C$ is length change of fabric samples in percentage, $A$ is original length of fabric sample before washing and drying, and $B$ is length of fabric sample after washing and drying. All of the specimens were measured after being conditioned in the standard atmosphere of $65( \pm 3) \% \mathrm{RH}$ and $20( \pm 2){ }^{\circ} \mathrm{C}$ for at least $16 \mathrm{~h}$.

\subsubsection{Relative Humidity $(\mathrm{RH})$ of outlet air}

IButtons (DS 1923), being able to measure the Relative humidity (RH) between 0 and $100 \%$, were fixed on outlet of the tumble dryer to measure the relative humidity of outlet air every 6 seconds during the tumble drying process at the rotation speed of 16 $\mathrm{rpm}, 35 \mathrm{rpm}$ and $51 \mathrm{rpm}$, or every 12 seconds at the rotation speed of $67 \mathrm{rpm}$.

2.3.6 The degree of total mechanical action applied on fabrics 
Mechanical action on fabrics in a tumble dryer could be influenced by the speed of tumble rotation. The percentage of thread removal of a specific polyester woven fabric, which was called "thread removal fabric", was used to characterize the degree of total mechanical action on fabrics. ${ }^{16,30}$ The measuring method was carried out with reference to EMPA 304 (IEC PAS 62473-2007) ${ }^{31}$. The thread removal fabric was stitched and fixed on the center of the wool fabric sample. In each test, 5 pieces of the thread removal fabrics were used. The percentage of thread removal of the fabric was calculated using Equations (4)-(6) based on IEC PAS 62473-2007.

$$
\begin{aligned}
& A_{\text {warp }}=\frac{T_{\text {warp }, o}-T_{\text {warp }, r}}{T_{\text {warp }, o}} \cdot 100 \% \\
& A_{\text {wef } t}=\frac{T_{\text {weft }, o}-T_{\text {weft }, r}}{T_{\text {weft }, o}} \\
& A=\frac{A_{\text {warp }}+A_{\text {weft }}}{2}
\end{aligned}
$$

Where $A_{\text {warp }}$ is the percentage of warp thread removal from the whole "thread removal fabric", $A_{\text {weft }}$ is the percentage of weft thread removal, $A$ is the percentage of thread removal; $T_{\text {warp }, o}$ is the average length across the original warp woven structure, and $T_{\text {warp, },}$ is average length across the remaining warp woven structure; $T_{\text {weft,o }}$ is average length across the original weft woven structure, and $T_{w e f t, r}$ is average length across the remaining weft woven structure.

\section{Results and discussion}

3.1 Drying performance at different fabric movements with the load of $2 \mathrm{~kg}$

$2 \mathrm{~kg}$ of wool fabrics including untreated wool fabrics, Chlorine-Hercosett treated wool and wool makeup weight were dried together in tumble dryer at different rotation speeds of drum. The initial moisture content of wool fabric load was controlled at $60 \%$ and drying process was stopped when the moisture content of the fabrics reached $6 \%$ or less. During the drying process, fabric movement, drying efficiency and evenness, and fabric performances including fabric smoothness and fabric shrinkage were explored.

\subsubsection{Specific moisture extraction rate (SMER)}

Tumble dryers have been increasingly used for drying garments after washing. Energy use is more concerned by the consumers. The effect of rotation speed of drum on the energy efficiency of drying wool fabrics in term of specific moisture extraction rate (SMER) at same heater power of $3 \mathrm{~kW}$ and air flow velocity of $5.5 \mathrm{~m} / \mathrm{s}$ in the tumble dryer was investigated. To some degree, energy consumed during tumble drying depended on total drying time in the current study because the heater power was a fixed 
parameter, therefore the change of SMER (the ratio between the amount of evaporated water and the total energy supply) at different rotation speeds of the drum was similar to that of drying efficiency (the ratio between the amount of evaporated water and total drying time). Figure 4 shows the SMERs at different rotation speeds of the drum at 16, 35,51 and $67 \mathrm{rpm}$, respectively. It is expected that when the rotation speed of the drum at $67 \mathrm{rpm}$ was high enough to make fabric adhered to the drum wall and rotated at the same speed with the drum, energy efficiency for drying fabrics was very low. Under this condition, only a small part of fabrics on the surface are able to contact with the hot air, and the heat exchange between fabrics and hot air was very limited, so most of the hot air was exhausted directly. RH (relative humidity) of outlet air was at a low level during drying, as shown in Figure 5a. This could explain the reason why the much longer drying time needed when the rotation speed of the drum is $67 \mathrm{rpm}$ (Table 1).

Under the rotation speeds at $16 \mathrm{rpm}, 35 \mathrm{rpm}$ and $51 \mathrm{rpm}$, the fabrics experienced different fabric movements in the tumble dryer. It is found that the energy efficiency for drying the fabrics at speed of $35 \mathrm{rpm}$ was higher than that at the speed of $16 \mathrm{rpm}$ and 51 rpm. This indicates that the heat exchange between hot air and fabrics through the projectile motion with tumbling occasionally at $35 \mathrm{rpm}$ could be higher than that through tumbled motion in the limited space at $16 \mathrm{rpm}$ or projectile and rotating motion at $51 \mathrm{rpm}$. The height of projectile and complexity of the motion could be the main factor for the influence on the drying efficiency in the tumble dryer. ${ }^{15}$ Figure $5 \mathrm{~b}$ shows the relative humidity of outlet air at different rotation speeds at the first 50 min drying time. It was found that the relative humidity of outlet air was at the order: $\mathrm{RH}_{35 \mathrm{rpm}}>$ $\mathrm{RH}_{51 \mathrm{rpm}}>\mathrm{RH}_{16 \mathrm{rpm}}>\mathrm{RH}_{67 \mathrm{rpm}}$ during the main drying period, and this could also reflect their different drying efficiency or energy efficiency.

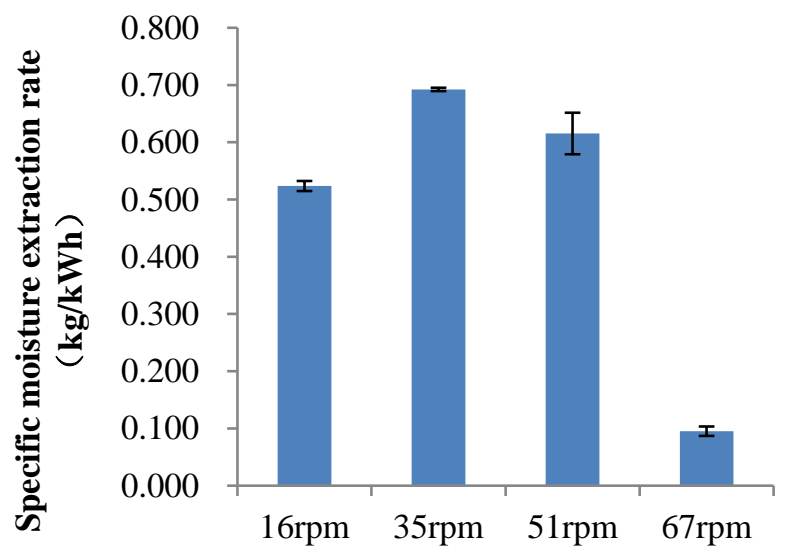

Rotation speed of the drum 
Figure 4 Specific moisture extraction rate (SMER) at different rotation speeds of the drum in the tumble dryer

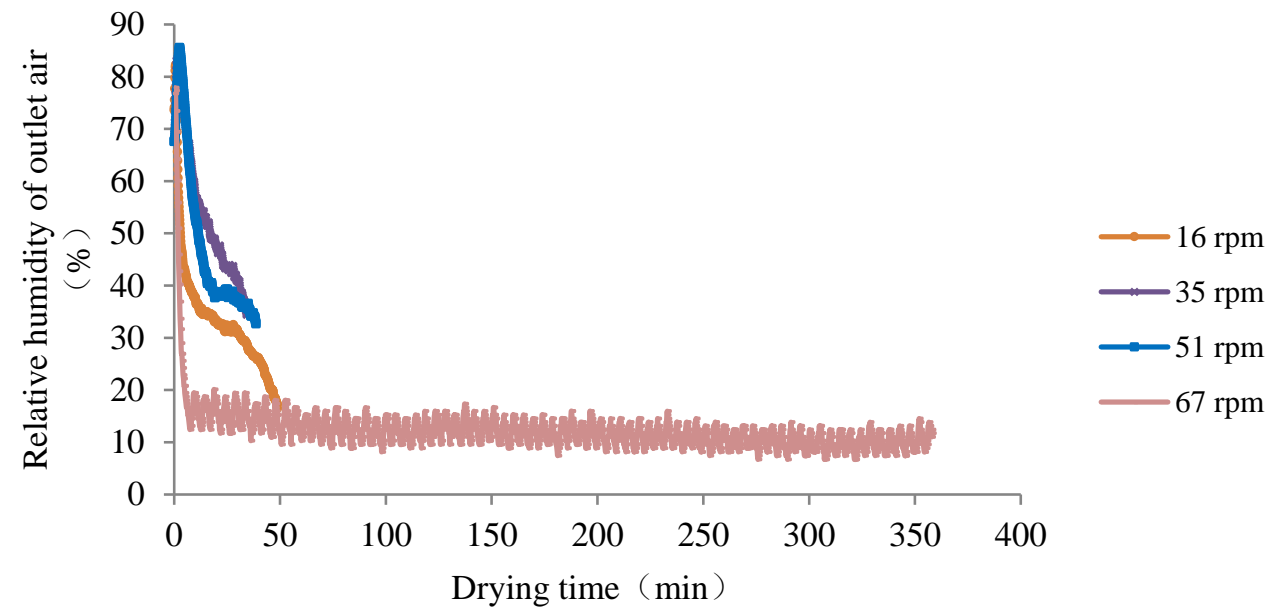

(a)
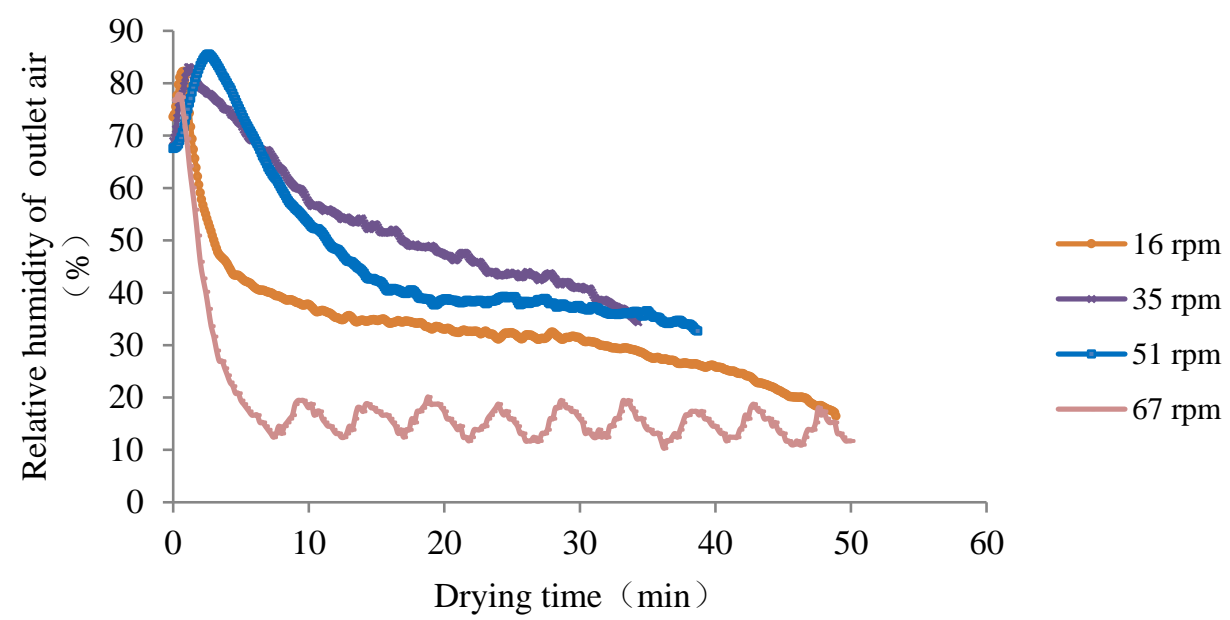

(b)

Figure 5 Relative humidity of outlet air from tumble dryer at different drying time and different rotation speeds during the whole drying cycle (a) or during the first $50 \min (b)$

\subsubsection{Evenness of drying}

Drying load of $2 \mathrm{~kg}$ fabrics might have concern on the evenness of fabric dry. Evenness of drying can be reflected from the difference between the final moisture contents of different wool fabric samples after drying. The effect of different drying speeds of drum rotation during tumble dry on the drying evenness of fabrics was investigated. Figure 6 shows the dry evenness of wool fabrics after tumble drying at different rotation speeds of the drum. It was found that uniformity of fabric drying at the rotation speeds of $35 \mathrm{rpm}$ and $51 \mathrm{rpm}$ was the best, because almost all fabric samples 
were projected in unfolded form to have better heat exchange between fabric and hot air in the tumble drying process. During tumbling motion at the rotation speed reduced to $16 \mathrm{rpm}$, some fabric samples could be surrounded by other fabric samples and rarely contact with the hot air during drying, without sufficient exchange between fabrics and hot air during drying, which impeded moisture evaporation to cause poor drying uniformity. At the high rotation speed of $67 \mathrm{rpm}$, it is expected that the uniformity of fabric drying is poor. That is because that fabric samples adhered to the wall of the drum at the same rotating movement with drum, so that the fabrics closed to the heater, or contacted directly with hot air could dry much more rapidly than the fabrics that were far away from the heater, or the fabric folded underneath that do not contact hot air.

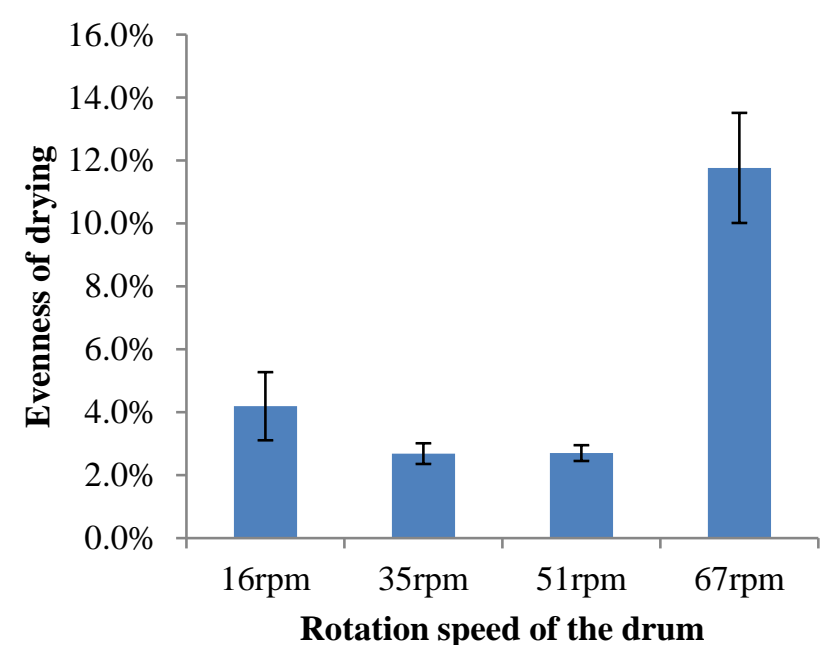

Figure 6 Evenness of drying of wool fabrics at different rotation speeds of the drum

\subsubsection{Fabric smoothness grade}

Fabric crease could occur not only during machine-washing but also during tumble drying. Maintenance of fabric smooth appearance after washing and drying processes is important. During tumble drying process, crease of fabrics occurs under heat, moisture and mechanical force. Hydrogen bonds between polypeptides in the amorphous region of wool fibers could be broken under stretching and/or folding at the wet and hot conditions. $^{32}$ During the drying process, the new bonds between polypeptides could reform at new positions under the external force on the crease of fabrics. ${ }^{32}$ Even when the external force is removed, creases could be remained on the fabrics after tumble drying. ${ }^{32}$ Mechanical force on fabrics during the tumble-drying process is influenced by the speed of tumble rotation to cause different extent of fabric deformation. The performance of wool fabrics in the term of fabric smoothness during tumble drying at 
different rotation speed was assessed. Table 3 shows the surface appearance of untreated wool fabrics and their smoothness grades after tumble drying at different rotation speeds. It was found that the fabric smoothness after drying at drum rotation speeds of $16 \mathrm{rpm}$ and $67 \mathrm{rpm}$ was much poorer than that at middle rotation speeds of $35 \mathrm{rpm}$ and $51 \mathrm{rpm}$. This is because that at the drum rotation speed of $16 \mathrm{rpm}$ fabrics tumbled in a limited space and were often squeezed by other fabric samples, resulting in the wrinkle of the fabrics, whereas the fabrics at the high rotation speed of $67 \mathrm{rpm}$ were pushed to adhere on the drum and rotated with the drum, resulting in the folded wrinkle of the fabric.

For comparing between untreated wool fabric and Chlorine-Hercosett treated wool fabric, it was noted that there was no significant difference in the fabric surface smoothness between them after one drying cycle.

Table 3 Smoothness grade and surface appearance of untreated wool fabrics after tumble drying at different rotation speeds

\begin{tabular}{|c|c|c|c|c|}
\hline $\begin{array}{c}\text { Rotation } \\
\text { speed (rpm) }\end{array}$ & 16 & 35 & 51 & 67 \\
\hline Movement & $\begin{array}{c}\text { Tumbling in a } \\
\text { small area } \\
\text { with tumbling } \\
\text { occasionally }\end{array}$ & $\begin{array}{c}\text { Projectile motion } \\
\text { partial rotating } \\
\text { motion }\end{array}$ & $\begin{array}{c}\text { Rotating with } \\
\text { drum }\end{array}$ \\
\hline $\begin{array}{c}\text { Smooth } \\
\text { appearance } \\
\text { of fabrics } \\
\text { grade) }\end{array}$ & 2.8 & 3.8 & 3.8 & 2.5 \\
\hline $\begin{array}{c}\text { Image of } \\
\text { fabric } \\
\text { samples }\end{array}$ & & & & \\
\hline
\end{tabular}

\subsubsection{Dimensional change of wool fabric}

The change in dimension of wool fabric caused by tumble drying is one of the most important criteria to assess the performance of wool fabrics or garments. Wool garments could no longer be serviceable if severe shrinkage occurs during laundering or tumble drying. Figure 7 shows the length changes of untreated and Chlorine-Hercosett treated wool fabrics after tumble drying at different rotation speeds of the drum. Significant difference in shrinkage of fabrics between the untreated and shrink-resist treated wool 
fabrics was noted as expected.

Untreated wool fabric shrinks during tumble drying mainly due to felting. Felting is the process of progressive entanglement of fibers in an assembly, which occurs as a result of persistent rootward migration of fibers due to the directional frictional effect (DFE) of cuticle scale-configured wool fibers. ${ }^{33}$ During the drying process, felting shrinkage of wool fabric was influenced by the moisture content of fabric, temperature of fabric and mechanical action being applied on the fabric. ${ }^{34}$ Under different rotation speeds of drum in tumble dryer, felting shrinkage is greatly depending on mechanical action. As shown in Figure 7, shrinkage of untreated wool fabric changed with the rotation speed of the drum. When the rotation speed of the drum was at 16, 35 or $51 \mathrm{rpm}$, the severer shrinkages of untreated wool fabric between $10 \%$ to $14 \%$ occurred. This is because that the fabrics experienced the strong mechanical action from tumbling, projectile and impact onto the drum at these rotation speeds of the drum during tumble drying process. Severity of mechanical action impacted on wool fabrics can be monitored from the fabric thread removal test as shown in Figure 8. It is confirmed that the wool fabric suffered the higher mechanical action at the rotation speed of 16, 35 and $51 \mathrm{rpm}$ respectively based on the higher thread removal from the fabric. It is understandable that in general the severer the mechanical action, the greater the felting shrinkage of wool fabric, because the greater mechanical force applied on fabrics could promote fibers to migrate and entangle.

Under the rotation speed at $67 \mathrm{rpm}$, the shrinkage of untreated wool fabric was less than $3 \%$. This is because that the fabric adhered to the wall of drum and rotated with the drum at high speed. There was minimum mechanical action applied on the fabrics, which was also confirmed from the lowest thread removal from fabrics as shown in Figure 8 .

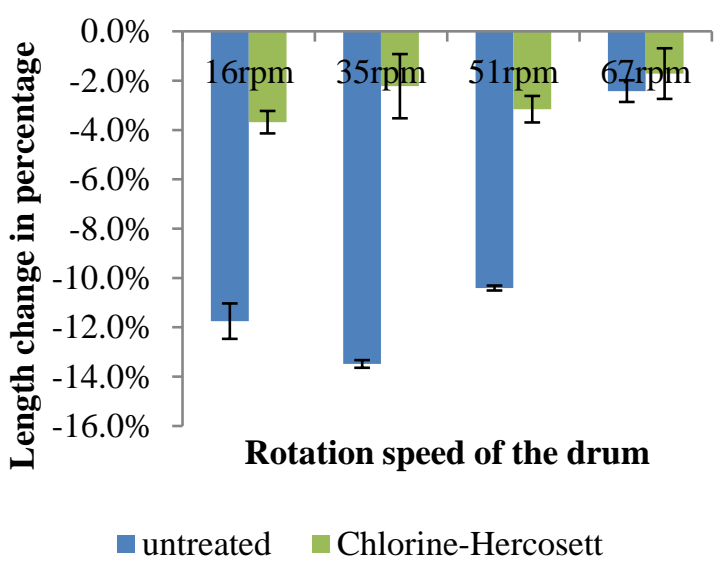

Figure 7 Length change of wool fabrics at different rotation speeds of the drum 


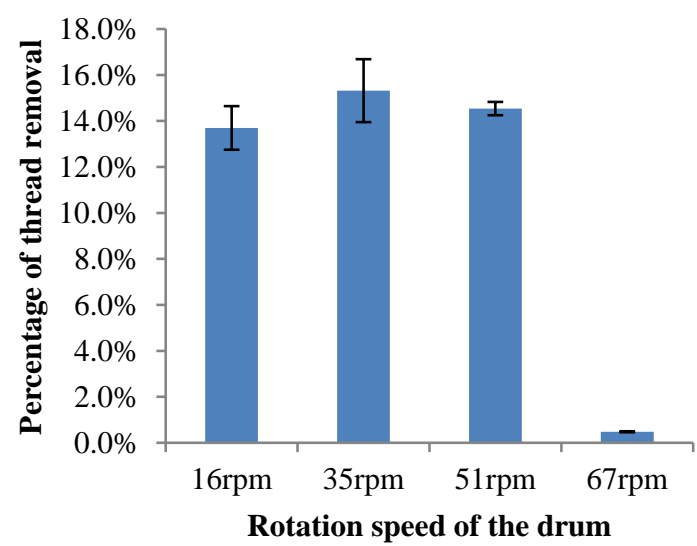

Figure 8 Mechanical action severity experienced by the thread removal fabric at different rotation speeds of the drum

For Chlorine-Hercosett treated wool fabric, the change in dimension of wool fabric after tumble drying maintained at $1 \%$ to $4 \%$ of shrinkage. Chlorine-Hercosett treated wool fabric can withstand the tumble drying at different rotation speeds of drum in the tumble drying process within the acceptable shrinkage, because cuticle scales on the surface of wool fibers were partially degraded by chlorination and covered with resin. The previous study showed that this shrinkage is not due to felting but reversible shrinkage. With moisture content of fibers decreasing, fibers deswell, resulting in the voids or gaps appeared between the fibers. ${ }^{12,35}$ Mechanical agitation from the rotation of drum could make the voids or gaps collapsed, hence shrinkage could occur. ${ }^{12,35}$

\subsubsection{Overall assessment}

Understanding of fabric movement during tumble drying process in tumble dryer could explain dry efficiency, felting shrinkage, drying uniformity and appearance smoothness of wool fabrics. Optimum rotation speed of drying drum could be found for drying shrink-resist treated wool fabrics. According to the comparison of drying performances at different fabric movements, the rotation speed of $35 \mathrm{rpm}$ is a good choice for drying Chlorine-Hercosett treated wool fabric in tumble dryer. At this rotation speed, the fabrics are subjected to the projectile motion with tumbling occasionally.

However, for untreated wool fabric, as shown in Figure 7, the severe felting shrinkage of fabric at 16,35 or $51 \mathrm{rpm}$ of drum rotation could not be accepted. Although shrinkage of untreated wool fabric is relatively low after drying under rotating movement at $67 \mathrm{rpm}$, drying uniformity, fabric smoothness and SMER are poor. Therefore, alternative fabric movements for drying untreated wool fabric need to be 
explored. In order to avoid the rubbing between fabrics, which easily caused felting shrinkage of untreated wool fabric, ${ }^{16}$ drying performance with the load of only one fabric sample in the tumble dryer was investigated.

3.2 Drying performance of single fabric with different fabric movements in the tumble dryer

Flat dry without motion in the tumble dryer has been considered for drying wool fabric or garment in order to prevent felting shrinkage of wool. However, the drying efficiency of flat dry is significantly lower than that of tumble dry. Design of flat dry with vertical movement might improve the heat exchange between the fabric and hot air. For untreated wool fabric, the flat dry of single piece of wool fabric in the tumble dryer without motion and with vertical movement was investigated. The performance of flat dry of wool fabric was also compared to the tumble dry. Section 3.1 has shown that drying under projectile motion results in better specific moisture extraction rate (SMER), drying uniformity and fabric smoothness than tumbling motion in a small area or rotating at a high speed. Projectile movement may also reduce felting shrinkage because the mechanical force that is perpendicular to the fabric does not cause obvious felting shrinkage. ${ }^{10,16}$ Therefore, the current research explored the comparison of drying performance between flat dry and projectile-motion dry at the rotation speed of $31 \mathrm{rpm}$.

Three motions, which are (a) flat dry without motion, (b) flat dry with vertical movement and (c) the projectile motion, were implemented in the tumble dryer respectively by holding single piece of untreated wool fabric on the perforated shelf in the drum with the option of motionless or movement up and down manually, or by tumble dry of the single piece of untreated wool fabric at the rotation speed of $31 \mathrm{rpm}$. Table 4 showed the detail of the drying parameters and their results in term of drying time, shrinkage, SMER and fabric smoothness.

It is expected that SMER for drying the fabric at projectile motion was better than that for flat drying, but $4.6 \%$ in the reduction of fabric length occurred. After one cycle, two cycles and three cycles of drying the wool fabric under projectile motion at the rotation speed of $31 \mathrm{rpm}$, the length changes of the untreated wool fabric are $-4.6 \%,-8.2 \%$ and $-11.4 \%$. The felting shrinkage increased steadily after repeating soaking and projectile motion drying due to the mechanical force applied on the fabric caused by the slight rubbing between the fabric sample and the drum wall, and the flex of flexible fabric during impact.

When fabrics were flat dried either without motion or vertically movement, there was no significant shrinkage occurred. However, SMER of flat dry is lower than that of 
tumble dry under projectile motion. It is interesting to note that the moisture extraction rate of flat dry of single wool fabric with vertical movement $(0.054 \mathrm{~kg} / \mathrm{kWh})$ was higher than that of flat dry without motion $(0.039 \mathrm{~kg} / \mathrm{kWh})$ and closed to the moisture extraction rate of tumble dry of same size of wool fabric at the rotation speed of $31 \mathrm{rpm}$ $(0.059 \mathrm{~kg} / \mathrm{kWh})$. The possible reason for the positive effect of vertical movement is that the vertical movement of shelf with the fabric could disrupt the steady airflow conditions and change the distribution of drying air around the fabric sample, and this may improve mixing of airflow and interaction with the fabrics. Therefore, in order to prevent felting shrinkage of untreated wool fabric or garment, flat drying could be used in the tumble drying machine and vertical movement could be implemented to improve the moisture extraction rate, resulting in the energy saving.

Table 4 Drying parameters and performances of untreated wool fabric under different motions during drying at heater power of $3 \mathrm{~kW}$ and air flow velocity of $5.5 \mathrm{~m} / \mathrm{s}$ in the tumble dryer

\begin{tabular}{|c|c|c|c|c|c|c|c|}
\hline Parameters & & & & & Performances & & \\
\hline Load & $\begin{array}{c}\text { Fabric } \\
\text { movement }\end{array}$ & $\begin{array}{c}\text { Initial } \\
\text { moisture } \\
\text { content } \\
(\%)\end{array}$ & $\begin{array}{l}\text { Rotation } \\
\text { speed of } \\
\text { the drum } \\
(\mathrm{rpm})\end{array}$ & $\begin{array}{l}\text { Drying } \\
\text { time } \\
(\min )\end{array}$ & $\begin{array}{l}\text { Length change } \\
\text { of wool fabric } \\
(\%)\end{array}$ & $\begin{array}{c}\text { SMER } \\
(\mathrm{kg} / \mathrm{kW} \cdot \mathrm{h})\end{array}$ & $\begin{array}{c}\text { Smooth } \\
\text { appearance } \\
\text { of fabric } \\
\text { (grade) }\end{array}$ \\
\hline \multirow{3}{*}{$\begin{array}{l}\text { Single piece of } \\
\text { untreated wool } \\
\text { fabric }(65 \mathrm{~g})\end{array}$} & $\begin{array}{c}\text { Flat dry } \\
\text { (motionless) }\end{array}$ & \multirow{3}{*}{60} & 0 & 21.7 & -2.0 & 0.039 & 3.8 \\
\hline & $\begin{array}{c}\text { Flat dry with } \\
\text { vertical movement }\end{array}$ & & 0 & 15.5 & -1.1 & 0.054 & 3.7 \\
\hline & $\begin{array}{l}\text { Oblique projectile } \\
\text { motion }\end{array}$ & & 31 & 15.8 & -4.6 & 0.059 & 3.7 \\
\hline
\end{tabular}

\subsection{Recommendation of drying movement for wool fabrics}

According to the results of the experiments and the analysis from the current work, fabric movements for drying wool fabrics in the tumble dryer are recommended as shown in Table 5. Non machine-washable wool fabric, such as untreated wool fabric or garment could be dried by holding fabric or garment on the fixed perforated shelf with vertical movement in the tumble dryer to prevent felting shrinkage but compromised with consumption of energy, whereas the machine washable wool fabrics, such as Chlorine-Hercosett treated wool or garments could be dried in tumble dryer at the 
rotation speed to keep fabric movement under projectile motion accompanied with tumbling occasionally. Comparing with the existing flat drying (motionless) method in the modified tumble dryer, introducing of vertical movement in the flat drying method for drying the untreated wool fabric can increase the drying efficiency by more than $30 \%$, and the energy efficiency of the drying method for Chlorine-Hercosett treated wool fabric under projectile motion accompanied with tumbling occasionally was much higher.

It is recommended that consumers should be guided ${ }^{36}$ to check the washing and drying labels of clothes for using the recommended washing and drying methods.

Table 5 The recommendation of drying movements and performances of wool fabrics after drying

\begin{tabular}{cccccc}
\hline $\begin{array}{c}\text { Wool fabric and } \\
\text { drying load }\end{array}$ & $\begin{array}{c}\text { Fength } \\
\text { movement }\end{array}$ & $\begin{array}{c}\text { change of } \\
\text { wool fabric } \\
(\%)\end{array}$ & $\begin{array}{c}\text { SMER } \\
(\mathrm{kg} / \mathrm{kWh})\end{array}$ & $\begin{array}{c}\text { Evenness } \\
\text { of drying } \\
(\%)\end{array}$ & $\begin{array}{c}\text { Smooth } \\
\text { appearance of } \\
\text { fabric (grade) }\end{array}$ \\
\hline $\begin{array}{c}\text { Untreated wool } \\
\text { fabric (one piece, } \\
0.065 \mathrm{~kg})\end{array}$ & $\begin{array}{c}\text { Flat dry with } \\
\text { vertical } \\
\text { movement }\end{array}$ & -1.1 & 0.054 & 0 & 3.5 \\
\hline $\begin{array}{c}\text { Chlorine-Hercosett } \\
\text { treated wool fabric }\end{array}$ & $\begin{array}{c}\text { Projectile motion } \\
\text { with tumbling } \\
(2 \mathrm{~kg})\end{array}$ & -1.6 & 0.668 & 2.30 & 3.5 \\
\hline
\end{tabular}

\section{Conclusions}

Tumble dryers are widely used for drying garments, but felting shrinkage could be caused to wool garments during tumble drying process. In order to dry wool fabrics or garments in tumble dryers, flat dry function has been introduced in the dryers, however the energy efficiency is very low.

The current study investigated the fabric movement during drying at different rotation speeds in the tumble dryer. Four major movements of fabrics during tumble drying were identified as tumbling, projectile motion accompanied with occasionally tumbling, projectile motion with rotating, and fully rotating with the drum corresponding to the different rotation speeds.

For machine-washable wool fabrics, tumble drying at the rotation speed to keep fabric movement under projectile motion accompanied with occasionally tumbling could achieve better energy efficiency, drying uniformity and smoothness appearance of fabric. 
However, for wool fabrics that are not machine-washable including untreated wool fabric, flat dry without motion in the tumble dryer has been considered in order to prevent wool felting shrinkage. Introducing of vertical movement for the flat dry in the tumble dryer could improve the heat exchange between the fabric and hot air, resulting in the higher energy-efficiency than flat drying motionlessly.

The results from the current study could contribute to the knowledge for understanding the fabric movement during tumble drying and help tumble dryer manufacturers to design appropriate drying methods for wool fabrics with the potential for the energy saving. This could provide the guidance for consumers and drying labelling for wool garments.

\section{Acknowledge}

The funding supports to this research are provided by National Key R\&D Program of China through project 2019YFB1706304, and the Fundamental Research Funds for the Central Universities (Grant NO. 2232020G-08).

\section{References}

1. Van der Vegt AK. A study on the mechanism of wool felting. PhD Thesis, Delft University of Technology, Netherlands, 1955.

http://resolver.tudelft.nl/uuid:fdacc136-4c23-4870-a24c-8cf2f8791458

2. Millington, K.R. and Rippon J.A.. Wool as a high-performance fiber. In: Bhat, G. (eds.) Structure and Properties of High-Performance Fibers. Cambridge: Woodhead Publishing, 2017, pp. 367-408. https://doi.org/10.1016/B978-0-08-100550-7.00014-0

3. Foulds, C., Powell, J.and Seyfang, G.. How moving home influences appliance ownership: a Passivhaus case study. Energy Effic 2016; 9: 455-472. https://doi.org/10.1007/s12053-015-9364-0

4. Breadsell, J.K., Morrison, G.M.. Changes to household practices pre- and post-occupancy in an Australian low-carbon development. Sustainable Production and Consumption 2020; 22: 147-161. https://doi.org/10.1016/j.spc.2020.03.001

5. U. S. Energy Information Administration, Office of Energy Consumption and Efficiency Statistics.

$\begin{array}{llll}\text { Residential Energy } & \text { Consumption } & \text { Survey }\end{array}$
https://www.eia.gov/consumption/residential/data/2015/hc/php/hc3.1.php. (2017, accessed 9 August 2020)

6. Peng, C. Momen, A.M., Moghaddam, S.. An energy-efficient method for direct-contact ultrasonic cloth 
drying. Energy 2017; 138: 133-138. https://doi.org/10.1016/j.energy.2017.07.025

7. Gluesenkamp, K.R., Boudreaux P., Patel, V.K.,et al. An efficient correlation for heat and mass transfer effectiveness in tumble-type clothes dryer drums. Energy 2019: 172: 1225-1242. http://orcid.org/0000-0002-0053-8789

8. Haines, V., Lomas K., Thomson, M., et al. (2010). How trends in appliances affect domestic $\mathrm{CO}_{2}$ emissions: a review of home and garden appliances summary report. Report, Loughborough University, UK, January 2010. https://repository.lboro.ac.uk/articles/report/How_trends_in_appliances_affect_ domestic_CO2_emissions_a_review_of_home_and_garden_appliances_summary_report/9354311

9. Morgan, E., Foxon, T.J.. 'I prefer $30^{\circ}$ '?: Business strategies for influencing consumer laundry practices to reduce carbon emissions. J. Clean. Prod. 2018; 190: 234-250. https://doi.org/10.1016/j.jclepro.2018.04.117

10. Rippon J.A.. Friction, felting and shrink-proofing of wool. In: Gupta, B.S. (eds.), Friction in Textile Materials. Cambridge: Woodhead Publishing, 2008, pp. 253-291. https://doi.org/10.1533/9781845694722.2.253

11. Shen, J.. Wool finishing and the development of novel finishes. In: Johnson, N.A.G. \& Russell, I.M. (eds.) Advances in Wool Technology. Cambridge: Woodhead Publishing, 2009, pp. 147-182. https://doi.org/10.1533/9781845695460.1.147

12. Bao, W., Shen, J., Ding X., Wu X.. Dimensional change of wool fabrics in the process of a tumble-drying cycle. Text. Res. J. 2019; 89: 4702-4709. https://doi.org/10.1177/0040517519841370

13 Laitala, Kirs and Klepp, Ingun Grimstad. Wool Wash: Technical Performance and Consumer Habits. Tenside Surfact Det 2016; 53(5): 458-469.

https://www.webofscience.com/wos/alldb/full-record/WOS:000388271800008

14. Denby E. The severity of impeller washing machines. Text Res $J$ 1980; 50: 416-419.

15. Wei, Y., Su, Z., Zhang, Y., et al.. The effect of fabric movement on drying performance of the domestic drum dryer. J. Text. Inst. 2019; 110: 1059-1071. https://doi.org/10.1080/00405000.2018.1537104

16. Bao, W., Shen, J., Ding X. The influence of mechanical action on felting shrinkage of wool fabric in the tumble dryer. Text. Res. J. 2020; 90: 2367-2375. https://doi.org/10.1177/0040517520918665

17. Stawreberg, L., Wikstrom, F.. Does the energy labelling system for domestic tumble dryers serve its purpose?. J. Clean. Prod. 2011; 19: 1300-1305. https://doi.org/10.1016/j.jclepro.2011.03.016

18. Yu, X., Li, Y., Ding X.. Dynamics of cotton textile motion in a domestic tumble dryer and its effect on drying performance. Text. Res. J. 2021; 91: 851-873. 
19. Gataric, P., Sirok, B., Hocevar, M., Novak, L.. Influence of load mass, drum speed and load composition on evenness of drying in a heat pump tumble dryer. Drying Technology 2021. DOI: 10.1080/07373937.2021.1928688. https://doi.org/10.1080/07373937.2021.1928688

20. Whewell, C. S., Rigelhaupt, L., Selim, A.. Mechanism of the Milling Shrinkage of Wool Fabrics. Nature 1944; 154: 772-772. https://doi.org/10.1038/154772a0

21. Makinson, K.R.. Shrinkproofing of Wool. New York: Marcel Dekker Inc., 1979.

22. Hassan, M.M., Carr C.M.. A review of the sustainable methods in imparting shrink resistance to wool fabrics. J. Adv. Res. 2019; 18: 39-60. https://doi.org/10.1016/j.jare.2019.01.014

23. Mori, M., Matsudaira, M.. Comparison of woolen eco-friendly anti-felting treatment with classic anti-felting procedures. Text. Res. J. 2013; 83: 208-215. https://doi.org/10.1177/0040517512458343

24. Woolmark Test Method - TWC - TM309. Performance of Domestic Tumble Driers for "Hand Wash" Wool Products.

25. Wei, Y., Gong, R.H., Ning, L., et al. Enhancing the energy efficiency of domestic dryer by drying process optimization. Dry. Technol. 2018; 36: 790-803. https://doi.org/10.1080/07373937.2017.1356329

26. Stawreberg, L., Nilsson, L.. Modelling of specific moisture extraction rate and leakage ratio in a condensing tumble dryer. Appl. Therm. Eng. 2010; 30: 2173-2179. https://doi.org/10.1016/j.applthermaleng.2010.05.030

27. GB/T 20292: 2006. Tumble dryers for household use-Methods for measuring the performance.

28. AATCC Test Method 124: 2014. Smooth appearance of fabrics after repeated home laundering.

29. AATCC Test Method 135: 2014. Dimensional Changes in Automatic Home Laundering of Woven or Knitted Fabrics.

30. Bao W, Gong R H, Ding X, et al. Optimizing a laundering program for textiles in a front-loading washing machine and saving energy[J]. J Clean Prod 2017; 148: 415-421.

31. IEC PAS 62473: 2007. Clothes washing machines for household use-Methods for measuring the mechanical action in household washing machines.

32. Park, S., Kim, K., Yun, C. et al. Influence of Drying Conditions on the Wrinkling of Fabrics. Fiber Polym 2020; 21(12): 2993-2999. 
33. Makinson KR. Studies of the movement of wool fibers in fabrics during felting, with particular reference to the permanency of pleats: part III: felting in a woolen fabric. Text Res $J 1960$; 30: 598-606.

34. Bao W, Shen J, Ding X, The influence of moisture content on shrinkage of wool fabrics during domestic tumble drying process. Fiber Polym 2021; 22(2): 559-566.

35. Higgins L, et al. Effect of tumble-drying on selected properties of knitted and woven cotton fabrics: part II: effect of moisture content, temperature setting, and time in dryer on cotton fabrics. $J$ Text I 2003; 94: 129-139.

36. Ellmer, K., Fuchs, M., Bauer, U., et al. Research project Simulation Waschepflege - Recommendations for improving resource efficiency in the laundry process in households in Germany. J. Clean. Prod. 2017; 153: 539-547. https://doi.org/10.1016/j.jclepro.2015.07.157. 